\title{
Mean platelet volume and other hematological parameters in pediatric migraine
}

\author{
Yılmaz Akbaş iD \\ Pediatric Neurology Department, Mustafa Kemal University School of Medicine, Hatay, Turkey
}

\begin{abstract}
Introduction: According to our hypothesis, the mean platelet volume (MPV) value in migraine patients should be lower than in healthy individuals due to recurrent neuroinflammation during headache attacks. Therefore, this study aimed to identify differences between MPV and other hemogram parameters between pediatric patients with migraine and a healthy control group.
\end{abstract}

Material and methods: This study included a total of 80 people, 40 patients and 40 control subjects. Those with hematological diseases, using alcohol or smoking, with malignancy, pregnancy, or with any chronic disease were excluded from the study.

Results: Individuals in the control group were chosen to have the same age and same sex as the patient group $(p=0.98)$. The patient group had statistically significantly higher platelet counts than the control group $(p=0.043)$. MPV was lower in the patient group compared to the control group $(p=0.001)$, but platelet distribution width was higher in the patient group compared to the control group $(p=0.034)$

Conclusions: Migraine patients in the pediatric period were shown in our study to have low MPV values and elevated platelet counts due to recurrent neuroinflammation. This result shows that inflammation especially plays a vital role in migraine pathophysiology.

Key words: pediatric migraine, platelets, hematological parameters, mean platelet volume

Acta Haematologica Polonica 2022; 53, 1: 53-57

\section{Introduction}

Headache is a health problem known from ancient times, and nearly everyone experiences it at least once in their lifetime. It is the commonest cause of presenting to emergency services. The International Headache Society (IHS) has divided headaches into three groups: primary, secondary, and other headaches [1]. Migraine, recurrent headache attacks with stress-type pain, comprises most primary headache classes [2]. The most commonly suggested hypothesis for migraine pathophysiology is the trigeminovascular pathway hypothesis [3]. According to this hypothesis, vasodilation in the meningeal arteries causes the activation of inflammatory neuropeptides and inflammation in the brain tissue, activating the trigeminal system and initiating a vicious cycle. As a result, there is ongoing inflammation in the brain tissue. Neurogenic inflammation causes the release of vasoactive peptides such as neurokinin A, substance $P$ from trigeminal and parasympathetic fibers. These vasoactive peptides release pro-inflammatory mediators such as prostanoids and bradykinin, causing vasodilation and extravasation. Thus, the event cycle of migraine occurs.

It is well known that lymphocytes and other leukocytic serial cells play roles in inflammation. Studies have been

\footnotetext{
Address for correspondence: Yılmaz Akbaş, Hatay Mustafa Kemal University School of Medicine Pediatric Neurology Department, 31010 Serinyol/Hatay, Hatay, Turkey, phone +90 53956595 92, e-mail: mberf@hotmail.com

PTHiT copyright $\odot 2022$

The Polish Society of Haematologists and Transfusiologists, Insitute of Haematology and Transfusion Medicine. All rights reserved.
} 
performed recently showing variations related to inflammation of another hematological parameter, mean platelet volume (MPV). MPV is a standard hematological parameter demonstrating platelet functions. It can be easily measured with hemogram tests. Platelets that are more active in metabolic and enzymatic terms and with thrombogenic potential have a larger volume, while they have smaller volumes in situations related to chronic inflammation [4]. Due to the association with neurogenic inflammation, studies have been performed investigating whether there is a correlation between migraine and hemogram parameters. Some studies have identified significant correlations between migraine and MPV, while others have not $[5,6]$. The common denominator of these studies is that they have generally been performed in adult patients. There have been few studies with pediatric patients [7].

According to our hypothesis, the MPV value should be lower in migraine patients than in healthy individuals due to recurrent neuroinflammation during headache attacks. Therefore, this study aimed to identify differences between MPV and other hemogram parameters between pediatric patients with migraine and a healthy control group.

\section{Material and methods}

This study included a total of 80 children, with 40 patients and 40 control subjects. The patient group was chosen from patients (6-18 years) who attended the Pediatric Neurology Clinic at Mustafa Kemal University School of Medicine, Hatay, Turkey with headache and who received a migraine diagnosis according to the IHS diagnostic criteria [1] (Table I). The control group was chosen from healthy children attending the hospital in the same distributions of gender and age. Those with iron, vitamin $\mathrm{B}_{12}$ or folic acid deficiency, with anemia or other hematological diseases, who were using alcohol or smoking, with any malignancy, pregnancy, with any chronic disease (e.g. hypertension, diabetes, pulmonary, renal, liver diseases), with acute or chronic inflammatory disease, or using antibiotics were excluded from the study.

In our study, children's age, gender, ferritin, serum iron levels, iron-binding capacity, vitamin $\mathrm{B}_{12}$, folic acid and hemogram data were obtained from hospital files. In addition, the two groups were compared in terms of hemoglobin ( $\mathrm{Hb})$, white blood cell (WBC) count, platelets (PLT), neutrophil (Neu), lymphocyte (Lym), monocyte (Mon), MPV, platelet haematocrit (PCT), platelet distribution width (PDW) values, and neutrophil/lymphocyte (N/L), neutrophil/monocyte (N/M) and lymphocyte/monocyte (L/M) ratios.

For the study, blood samples were taken from arm veins in tubes containing ethylenediaminetetraacetic acid (EDTA) and stored at room temperature. Samples were studied within two hours. Complete blood count, thyroid hormones,
Table I. Migraine diagnostic criteria

\begin{tabular}{|c|c|}
\hline Migraine wi & Migraine with aura \\
\hline \multirow{6}{*}{$\begin{array}{l}\text { A. At least five attacks } \\
\text { [1] fulfilling criteria } \\
\text { B-D } \\
\text { B. Headache attacks } \\
\text { lasting 4-72 h (un- } \\
\text { treated or unsuccess- } \\
\text { fully treated) }[2,3]\end{array}$} & $\begin{array}{l}\text { A. At least two attacks fulfilling } \\
\text { criteria } B \text { and } C\end{array}$ \\
\hline & B. One or more of following fully \\
\hline & reversible aura symptoms: \\
\hline & 1. visual \\
\hline & 2. sensory \\
\hline & 3. speech and/or language \\
\hline \multirow{2}{*}{$\begin{array}{l}\text { C. Headache has at least } \\
\text { two of following four } \\
\text { characteristics: }\end{array}$} & 4. motor \\
\hline & 5. brainstem \\
\hline \multirow{3}{*}{$\begin{array}{l}\text { a) unilateral location } \\
\text { b) pulsating quality } \\
\text { c) moderate or severe } \\
\text { pain intensity }\end{array}$} & 6. retinal \\
\hline & C. At least three of following six \\
\hline & \\
\hline \multirow{3}{*}{$\begin{array}{l}\text { d) aggravation by, or } \\
\text { causing avoidance } \\
\text { of, routine physical } \\
\text { activity (e.g. walking } \\
\text { or climbing stairs) }\end{array}$} & $\begin{array}{l}\text { spreading gradually over } \\
\geq 5 \text { minutes }\end{array}$ \\
\hline & $\begin{array}{l}\text { 2. two or more aura symptoms } \\
\text { occurring in succession }\end{array}$ \\
\hline & 3. each individual aura symp- \\
\hline $\begin{array}{l}\text { D. During headache, at } \\
\text { least one of following: }\end{array}$ & $\begin{array}{l}\text { tom lasting 5-60 minutes } \\
\text { [1] }\end{array}$ \\
\hline \multirow{2}{*}{$\begin{array}{l}\text { a) nausea and/or } \\
\text { vomiting } \\
\text { b) photophobia and } \\
\text { phonophobia }\end{array}$} & $\begin{array}{l}\text { 4. at least one aura symptom } \\
\text { being unilateral [2] }\end{array}$ \\
\hline & $\begin{array}{l}\text { 5. at least one aura symptom } \\
\text { positive [3] }\end{array}$ \\
\hline \multirow[t]{2}{*}{$\begin{array}{l}\text { E. Not better accounted } \\
\text { for by another ICHD-3 } \\
\text { diagnosis }\end{array}$} & $\begin{array}{l}\text { 6. aura accompanied by, or } \\
\text { followed within } 60 \text { minutes } \\
\text { by, a headache }\end{array}$ \\
\hline & $\begin{array}{l}\text { D. Not better accounted for by } \\
\text { another ICHD-3 diagnosis }\end{array}$ \\
\hline
\end{tabular}

ICHD-3 $-3^{\text {rd }}$ edition of the International Classification of Headache Disorders

routine blood biochemistry, and C-reactive protein results were recorded.

Analysis of data used the IBM SPSS Statistics Version 21 program. Categoric measures were given as number and percentages, while fixed measures used mean \pm standard deviation (if necessary, median, min-max). The Kolmogorov-Smirnov test was used to determine whether data had parametric distribution or not. Investigating data with parametric distribution used the $t$-test, while non-parametric data was compared with the Mann-Whitney $U$ test. Statistically, values of $p=0.005$ and lower were accepted as significant.

\section{Results}

Eighty children were included in the study. Both the patient and the control group included 40 people, with 14 boys and 26 girls in each. The age range in the patient group was 6-18 years, while the age range in the control group was 
Table II. Ages and genders of patient and control groups

\begin{tabular}{|l|c|c|c|}
\hline Parameter & Patients & Controls & $p$ \\
\hline Age & $12.92 \pm 3.04$ & $12.8 \pm 3.07$ & 0.98 \\
Gender & $\mathrm{N}(\%)$ & $\mathrm{N}(\%)$ & \\
Male & $14(35)$ & $14(35)$ & \\
Female & $26(65)$ & $26(65)$ & \\
\hline
\end{tabular}

6-17 years. There was no significant difference between the patient and control groups regarding age $(p=0.98)$. The age intervals and gender distributions of both groups are set out in Table II.

The hemogram parameters and N/L, N/M and L/M ratios were compared in the patient and control groups (TabIe III). While the white blood cell value was slightly higher in the patient group, the hemoglobin value was higher in the control group. Still, there was no significant difference between the patient and control groups regarding hemoglobin and white blood cells $(p=0.181, p=0.761)$. The patient group had statistically significantly higher platelet counts than the control group. While the mean platelet count in the patient group was $311.75 \pm 82.79$ [mean \pm standard deviation (SD)], it was $275.52 \pm 74.21$ (mean \pm SD) in the control group $(p=0.043)$. When the specific parameters of platelets i.e. MPV, PDW and PCT, were compared, MPV was lower in the patient group than the control group $(p=$ $=0.001)$, PDW was higher in the patient group than the control group ( $p=0.034)$, and there was no difference between the two groups in terms of PCT value $(p=0.525)$. We did not identify any significant difference between the other hemogram parameters. Similarly, the N/L, N/M, L/M and $(\mathrm{P} / \mathrm{L})$ ratios were compared between the two groups. The most remarkable difference for these ratio comparisons was for the $\mathrm{P} / \mathrm{L}$ ratio, but no comparison provided statistically significant results (Table III).

\section{Discussion}

Platelets are known to play roles in thrombosis, angiogenesis and inflammation. MPV is a good marker of platelet activation. There is an increase in MPV values in thrombotic and cardiovascular diseases, while a fall occurs in inflammatory situations [4]. Many studies performed in recent years have shown a correlation between platelets and inflammation [8-14]. A common feature of these studies is that they were performed for chronic inflammatory diseases emerging outside the central nervous system (CNS). Among CNS diseases, the correlation between migraine and MPV has mainly been investigated $[6,7,15]$. In these studies, MPV values in migraine cases were higher [15], or not different from [6] those in the control group. Our study identified a statistically significant difference between the MPV values in the patient and control groups ( $p=0.001)$.

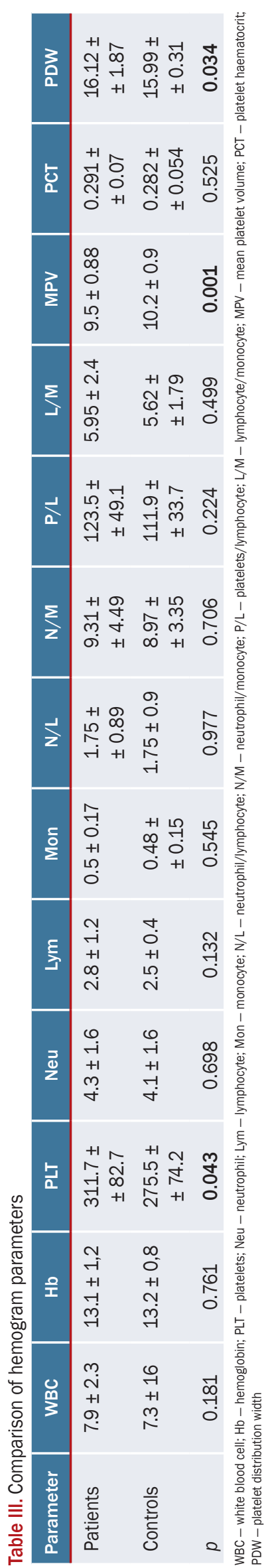


This difference was due to the patient group's MPV value being lower than the control group. The previous studies were performed with adult migraine patients. A study of pediatric migraine patients by Poyrazoğlu et al. in 2020 [7] compared a 56-person patient group to a 45-person control group, but found no significant difference between the groups.

In our study, unlike previous studies, the low MPV values in migraine patients were linked to recurrent neuroinflammation during migraine attacks in the brain. Studies investigating MPV association with inflammation have identified that the MPV values were lower than control groups. Two different studies of patients with inflammatory bowel disease showed low MPV and elevated platelet counts [8, 9].

Similarly, our study identified the platelet count as significantly higher compared to the control group. This suggests that the results obtained in our study could be related to continuing inflammation in the brain. Studies obtaining different results about migraine and MPV may be explained by performing studies in adult groups and by results being affected by age and gender differences between the patient and control groups. In addition to many hormonal and immunological agents playing a role in the maturation of thrombopoietic cells [16], thrombopoietin release levels differ between the genders. There are higher levels of thrombopoietin secretion in males, especially [17]. Our study set up our patient and control groups to have exactly the same numbers of male and female individuals in order to prevent MPV ratios from being affected by external factors. Additionally, we were very careful to ensure that the individuals in the control group were the same age as those in the patient group $(p=0.98)$. In both groups, individuals were chosen from among children without anemia and with serum iron, ferritin, folate, vitamin $\mathrm{B}_{12}$ and TSH levels within normal limits.

It is known that leukocyte series cells in blood play a leading role in pro-inflammatory and anti-inflammatory mechanisms [18]. Many studies have shown the correlation between $\mathrm{L} / \mathrm{M}, \mathrm{N} / \mathrm{M}, \mathrm{N} / \mathrm{L}$ and $\mathrm{P} / \mathrm{L}$ ratios and systemic inflammation [19-22]. These studies showed that different ratios were more valuable, but a ratio with a typical value could not be shown. In our study, significant differences were not identified for any of these ratios in the patient and control groups. This result shows that these ratios should be investigated on a disease basis, and that different diseases may provide different results.

\section{Conclusions}

Migraine patients in the pediatric period in our study revealed low MPV values and elevated platelet counts due to recurrent neuroinflammation. This shows that inflammation especially plays a vital role in migraine pathophysiology.

\section{Authors' contributions}

YA - sole author.

\section{Conflict of interest}

The author declares no conflict of interest.

\section{Financial support \\ No funding sources.}

\section{Ethics}

All the procedures performed in studies involving human participants followed institutional and/or national research committees' ethical standards and the 1964 Helsinki Declaration. The study protocol was approved by the Mustafa Kemal University School of Medicine Ethics Committee (2021/23).

\section{References}

1. Headache Classification Committee of the International Headache Society (IHS) The International Classification of Headache Disorders, 3rd edition. Cephalalgia. 2018; 38(1): 1-211, doi: 10.1177/ /0333102417738202.

2. Rasmussen BK. Epidemiology of headache. Cephalalgia. 2001; 21(7): 774-777, doi: 10.1177/033310240102100708, indexed in Pubmed: 11595011.

3. Ashina M, Hansen J, Do T, et al. Migraine and the trigeminovascular system -40 years and counting. Lancet Neurol. 2019; 18(8): 795-804, doi: 10.1016/s1474-4422(19)30185-1.

4. Gasparyan AY, Ayvazyan L, Mikhailidis DP, et al. Mean platelet volume: a link between thrombosis and inflammation? Curr Pharm Des. 2011; 17(1): 47-58, doi: 10.2174/138161211795049804, indexed in Pubmed: 21247392.

5. Brzeźniakiewicz-Janus K, Lancé MD, Tukiendorf A, et al. Is migraine an MPV-related disease? An observational study of Polish neurological patients. Dis Markers. 2019; 2019: 9454580, doi: 10.1155/ /2019/9454580, indexed in Pubmed: 31885744.

6. Sarıcam G. Relationship between migraine headache and hematological parameters. Acta Neurol Belg. 2021; 121(4): 899-905, doi 10.1007/s13760-020-01362-x, indexed in Pubmed: 32347450.

7. Poyrazoğlu HG, Öztürk AB. Predictive value of laboratory parameters in childhood migraine. Acta Neurol Belg. 2020; 120(4): 907-914, doi: 10.1007/s13760-019-01106-6, indexed in Pubmed: 30840223.

8. Kapsoritakis AN, Koukourakis MI, Sfiridaki A, et al. Mean platelet volume: a useful marker of inflammatory bowel disease activity. Am J Gastroenterol. 2001; 96(3): 776-781, doi: 10.1111/j.1572-0241.2001.03621.x, indexed in Pubmed: 11280550.

9. Yüksel 0 , Helvaci K, Başar O, et al. An overlooked indicator of disease activity in ulcerative colitis: mean platelet volume. Platelets. 2009; 20(4): 277-281, doi: 10.1080/09537100902856781, indexed in Pubmed: 19459134.

10. Shen J, Ran ZH, Zhang Y, et al. Biomarkers of altered coagulation and fibrinolysis as measures of disease activity in active inflammatory bowel disease: a gender-stratified, cohort analysis. Thromb Res. 2009; 123(4): 604-611, doi: 10.1016/j.thromres.2008.04.004, indexed in Pubmed: 18499234. 
11. Stamatelopoulos KS, Kitas GD, Papamichael CM, et al. Atherosclerosis in rheumatoid arthritis versus diabetes: a comparative study. Arterioscler Thromb Vasc Biol. 2009; 29(10): 1702-1708, doi: 10.1161/ ATVBAHA.109.190108, indexed in Pubmed: 19608975.

12. Kisacik B, Tufan A, Kalyoncu U, et al. Mean platelet volume (MPV) as an inflammatory marker in ankylosing spondylitis and rheumatoid arthritis. Joint Bone Spine. 2008; 75(3): 291-294, doi: 10.1016/j. jbspin.2007.06.016, indexed in Pubmed: 18403245.

13. Karabudak O, Ulusoy RE, Erikci AA, et al. Inflammation and hypercoagulable state in adult psoriatic men. Acta Derm Venereol. 2008; 88(4): 337-340, doi: 10.2340/00015555-0456, indexed in Pubmed: 18709301.

14. Makay B, Türkyilmaz Z, Unsal E. Mean platelet volume in children with familial Mediterranean fever. Clin Rheumatol. 2009; 28(8): 975-978, doi: 10.1007/s10067-009-1148-5, indexed in Pubmed: 19283330.

15. Ulusoy E. Use of MPV and MPV/PLT ratio in the differentiation of migraine and tension-type headache. Acta Haematol Pol. 2018; 49(1): 15-19, doi: 10.2478/ahp-2018-0003.

16. Kaushansky K. The molecular mechanisms that control thrombopoiesis. J Clin Invest. 2005; 115(12): 3339-3347, doi: 10.1172/ JCI26674, indexed in Pubmed: 16322778.

17. Butkiewicz AM, Kemona H, Dymicka-Piekarska V, et al. Platelet count, mean platelet volume and thrombocytopoietic indices in healthy women and men. Thromb Res. 2006; 118(2): 199-204, doi: 10.1016/j. thromres.2005.06.021, indexed in Pubmed: 16139337.
18. de Jager CPC, van Wijk PTL, Mathoera RB, et al. Lymphocytopenia and neutrophil-lymphocyte count ratio predict bacteremia better than conventional infection markers in an emergency care unit. Crit Care. 2010; 14(5): R192, doi: 10.1186/cc9309, indexed in Pubmed: 21034463.

19. Lee SM, Russell A, Hellawell G. Predictive value of pretreatment inflammation-based prognostic scores (neutrophil-to-lymphocyte ratio, platelet-to-lymphocyte ratio, and lymphocyte-to-monocyte ratio) for invasive bladder carcinoma. Korean J Urol. 2015; 56(11): 749-755, doi: 10.4111/kju.2015.56.11.749, indexed in Pubmed: 26568792.

20. Losada B, Guerra JA, Malón D, et al. Pretreatment neutrophil/lymphocyte, platelet/lymphocyte, lymphocyte/monocyte, and neutrophil/ /monocyte ratios and outcome in elderly breast cancer patients. Clin Transl Oncol. 2019; 21(7): 855-863, doi: 10.1007/s12094-0181999-9, indexed in Pubmed: 30506134.

21. Marín Hernández C, Piñero Madrona A, Gil Vázquez PJ, et al. Usefulness of lymphocyte-to-monocyte, neutrophil-to-monocyte and neutrophil-to-lymphocyte ratios as prognostic markers in breast cancer patients treated with neoadjuvant chemotherapy. Clin Transl Oncol. 2018; 20(4): 476-483, doi: 10.1007/s12094-017-1732-0, indexed in Pubmed: 28785911.

22. Shi J, Zhao W, Ying $\mathrm{H}$, et al. The relationship of platelet to lymphocyte ratio and neutrophil to monocyte ratio to radiographic grades of knee osteoarthritis. Z Rheumatol. 2018; 77(6): 533-537, doi: 10.1007/ s00393-017-0348-7, indexed in Pubmed: 28681116. 